\title{
0 que é família para você? Opinião de crianças sobre o conceito de família
}

\section{¿Qué es para ti una familia? Opinión de niños sobre el concepto de familia What does family Mean to you? Children's Uiew on the Concept of the Family}

\author{
Ilana Landim* \\ Pontificia Universidade Católica do Rio de Janeiro \\ Roberto Alves Banaco \\ Associação Paradigma Centro de Ciências e Tecnologia do Comportamento \\ Juliane Callegaro Borsa \\ Pontificia Universidade Católica do Rio de Janeiro
}

Doi: https://doi.org/10.12804/revistas.urosario.edu.co/apl/a.7178

\begin{abstract}
Resumo
As diferentes configurações familiares são parte da sociedade contemporânea e resultam em mudanças nas concepções de famílias existentes na sociedade, inclusive para as crianças. Este estudo teve como objetivo analisar as concepções de famílias segundo o relato verbal de crianças. Participaram dessa amostra 108 crianças, com idades entre cinco e 12 anos $(M=8,58 ; D P=1,54)$, residentes na cidade do Rio de Janeiro. Foi realizada a seguinte pergunta a cada uma delas: "O que é uma família para você?". As respostas foram armazenadas em formato de texto e áudio a fim de serem realizadas uma análise lexical com o uso do software IRaMuTeQ e uma análise de conteúdo, segundo proposta de Bardin. Os resultados indicaram que o foco das crianças permanece em famílias de configurações tradicionais. Observou-se, no entanto, que as famílias já são reconhecidas
\end{abstract}

pelas crianças do ponto de vista do afeto e de funções associadas ao cuidado e proteção.

Palavras-chaves: famílias; concepções; crianças.

\section{Resumen}

Las diferentes configuraciones familiares son parte de la sociedad contemporánea y resultan en cambios en las concepciones de familias existentes en la sociedad, incluso para los niños. Este estudio tuvo como objetivo analizar las concepciones sociales sobre la familia, según el relato verbal de los niños. Participaron 108 niños, con edades entre 5 y 12 años $(M=8,58$, DP $=1,54)$, residentes en la ciudad de Río de Janeiro. Se les realizó la pregunta: “QQué es para ti una familia?”. Las respuestas fueron almacenadas en formato de texto y audio para realizar un análisis léxico, con el uso del software IRaMuTeQ, y un análisis de contenido, según la propuesta de Bardin.

Dirigir correspondência à Ilana Landim. Correio eletrônico: ilanaclandim@gmail.com Ilana Landim ORCID ID: https://orcid.org/0000-0002-0239-5582 
Los resultados indican que los niños siguen asociando el concepto de familia con las configuraciones tradicionales. Se observó, sin embargo, que los niños ya reconocen la familia desde el punto de vista del afecto y de las funciones asociadas al cuidado y protección.

Palabras claves: familias; puntos de vista; niños.

\section{fbstract}

The different family settings are part of contemporary society and result in changes in the conceptions of existing families, including for children. This study aimed to analyze the conceptions of families according to the children's verbal report. A total of 108 children aged 5 to 12 years $(\mathrm{M}=8.58, \mathrm{SD}=1.54)$, living in the city of Rio de Janeiro, participated in this study. The following question was asked to each of them: "What does family mean to you?". The answers were stored in text and audio format in order to perform lexical analysis, using the IRaMuTeQ software, and content analysis, according to Bardin's proposal. The results indicated that the focus of the children remains in families of traditional configurations. It was observed, however, that from early years, children recognize families from the point of view of affection and functions associated with care and protection.

Keywords: Families; conceptions; children.

A palavra família tem origem no latim famulus (servente), utilizada para designar, no contex to de escravidão na Roma Antiga, indivíduos servos e/ ou escravos submetidos ao poder de um indivíduo dominador. Foi posteriormente associada ao conjunto de indivíduos (filhos e mãe) submetidos ao poder econômico e hierárquico de um homem, no caso, o pai. Esse poder era estabelecido por meio do casamento civil e/ou religioso (marido e mulher) e consanguinidade (pais e filhos) (Dias, 2017). Entende-se, por isso, que independentemente da época histórica a palavra família foi por muito tempo associada à dimensão de indivíduos subordinados a alguém do sexo masculino (Del Priore, 2016).
A ausência de reconhecimento, legitimação social e cívica de múltiplos papéis das mulheres, como o de mulher, profissional e mãe, incentivou-as a irem à luta em prol de conquistas sociais (Del Priore, 2016). Foram levantadas bandeiras como a do feminismo, do uso de contraceptivos para impedir a gravidez e a favor da decisão por uma carreira que não se restringia à vida doméstica, mas poderia também estar voltada para a realização profissional. Uma nova sociedade exigiu atualizações de âmbito jurídico, representadas pelo surgimento de leis que garantiram à mulher o direito da propriedade de bens por meio do trabalho sem que fosse preciso autorização do homem para trabalhar, além de concederem o direito à herança e a recorrer à guarda de filhos (Lei 4.121/1962, conhecida como o "Estatuto da Mulher Casada") e a que tornou possível a dissolução do casamento (Lei 6.515/1977) (Dias, 2017).

Os surgimentos destas leis prepararam o terreno para que o conceito de família fosse alargado na Constituição Federal de 1988 (Brasil, 1988). Na nova constituição, a família passou a ser reconhecida por meio da igualdade de direitos entre homens e mulheres. Dentre os avanços registrados foi dada tutela à união estável e à família monoparental, de maneira que mesmo os filhos concebidos de maneira externa ao casamento, bem como os adotivos, tiveram seus direitos legitimados (Dias, 2017).

As configurações familiares sofreram modificações para dar conta das demandas emergentes da sociedade. É possível citar, a partir disso, a inclusão de configurações como famílias homoafetivas, pluriparentais (ou binucleares, decorrentes de divórcio e de guarda compartilhada) (Rosa, 2013). Nesse sentido, famílias devem ser investigadas por pesquisas que busquem rever e atualizar o conceito e construto 'família'. Novos estudos podem dar vazão às novas compreensões de configurações familiares, no intuito de abordar como os indivíduos estão se comportando perante tais mudanças na sociedade. Poucos estudos (e.g., Rigg \& Pryor, 2007; Ribeiro, \& Cruz, 2013; Zabriskie \& McCormick, 2003), 
abordaram a construção verbal de crianças em torno de suas famílias. Isso porque o papel inicial da família é cuidar dos indivíduos, de maneira mais direta, das crianças. Ela prepara a criança para relacionar-se com o grupo social mais amplo (e.g., grupo educacional, religioso), os quais representam agências sociais controladoras dos comportamentos dos indivíduos. A família também controla o comportamento da criança ao ensinar a criança como se comportar (e.g., andar, falar, comer, vestir-se) a fim de minimizar a ocorrência de punição dessas outras agências controladoras (Skinner, 2003). Esse processo interfere no desenvolvimento da criança, na medida em que esse é um processo de individualização influenciado pelas interações do indivíduo com o ambiente mais próximo (Lathan, 2012).

Para o analista do comportamento é relevante conhecer a percepção e a construção do relato verbal da criança sobre como a família está influenciando no seu desenvolvimento. Ao avaliar as concepções de famílias para ela, levantam-se hipóteses mais fidedignas de influências culturais em grupos minoritários familiares (Tozze \& Bolsoni-Silva, 2018). Capta-se como o indivíduo e a cultura, por meio de agências de controle, relacionam-se, favorecendo o esclarecimento de como as contingências sociais definem a vivência de um grupo específico (como pensam, sentem, comportam-se) (Latham, 2012).

Uma das formas de conceitualização desse aculturamento seria encontrar relações entre palavras, que podem ser consideradas como produtos de relações comportamentais aprendidas (Catania, 2006a; 2006b). Segundo Catania (2006b), palavras podem corresponder a comportamentos. Elas interagem com os ambientes, umas com as outras e com outras modalidades de comportamentos. Suas propriedades comportamentais estão relacionadas com contingências não-verbais e as relações com tais contingências podem ficar distorcidas em virtude das contingências sociais manterem o comportamento verbal. Assim, palavras podem ser enfocadas como estímulos antecedentes, res- postas ou estímulos consequentes, que se mantêm em relações de contingências sociais reforçadoras.

Várias relações entre estímulos já foram descritas por autores que desenvolveram estudos experimentais sobre o comportamento verbal, e descreveram estruturas relacionais entre estímulos e estímulos, assim como entre estímulos e respostas - entre os quais as palavras se encaixam (Hayes, Fox, Gifford, Wilson, Barnes-Holmes \& Healy, 2001). Esses autores elaboraram a Teoria dos Enquadres Relacionais (RFT, do inglês Relational Frame Theory), que descrevem algumas relações principais, como as seguintes: 1) relações de coordenação, que são de semelhança ou identidade, aquelas que vêm depois do autoclítico "X é...., ou "igual a", ou "semelhante a". No caso deste estudo, o próprio instrumento de coleta instiga claramente a emissão de respostas de coordenação. A pergunta apresentada, como será melhor descrita adiante foi "O que é uma família para você?". O autoclítico "é" pede por palavras que se coordenem com a palavra "família"; 2) relações de oposição, que são relações do tipo que denota que "X não é igual a Y", ou "X é o oposto de Y" e 3) relações hierárquicas, nas quais um estímulo faz parte ou compõe outro estímulo e lhes dão significado. Por exemplo, "o leão é um felino", coloca o animal "leão" em uma classe maior de estímulos "felino", por causa de suas características comuns a outros animais que não sejam "leões" (Wilson \& Luciano, 2002). Considerando tais relações entre estímulos (palavras), o objetivo deste estudo é analisar as concepções de famílias segundo o relato verbal de uma amostra de crianças cariocas.

\section{Método}

\section{Participantes}

A amostra foi composta por 108 crianças cariocas entre cinco e 12 anos $(M=8,58 ; D P=1,54)$, sendo $57(52,8 \%)$ meninos e $51(47,2 \%)$ meninas, matriculadas no Ensino Fundamental I de escolas 
públicas $(18,5 \%, \mathrm{n}=20)$ e privadas $(81,5 \%, \mathrm{n}=$ 88 ) do Rio de Janeiro. Elas residiam nas seguintes zonas da cidade: $\operatorname{sul}(73,1 \%, \mathrm{n}=79)$, norte $(20,3 \%$, $\mathrm{n}=24)$, oeste $(2,7 \%, \mathrm{n}=3)$, central $(0,9 \%, \mathrm{n}=1)$ e rural $(0,9 \%, \mathrm{n}=1)$.

As famílias tinham renda familiar de um a três salários mínimos $(50,9 \%, \mathrm{n}=55)$, até um salário mínimo $(31,5 \%, \mathrm{n}=34)$, sem renda $(6,5 \%, \mathrm{n}=7)$, de três salários mínimos em diante $(4,6 \%, \mathrm{n}=5)$. Apenas sete $(6,5 \%)$ famílias não especificaram a renda da família. A maior parte das famílias era religiosa $(88,9 \%, \mathrm{n}=96)$. As principais religiões mencionadas foram católicas $(48,1 \%, \mathrm{n}=52) \mathrm{e}$ evangélicas $(29,5 \%, \mathrm{n}=32)$.

\section{Procedimentos éticos e de coleta}

Esta pesquisa seguiu as recomendações éticas da Resolução 510/2016 (CNS, 2016). O projeto foi aprovado pela Plataforma Brasil (CAEE 80702517.1.0000.8144). A escolha das escolas aconteceu por conveniência, considerando o acesso às instituições que mantinham parceria com o laboratório de pesquisa da universidade das autoras principais. Em cada uma das escolas foi entregue uma cópia resumida do projeto de pesquisa, uma carta de apresentação da pesquisa e uma carta de aceite a ser assinada pelo(a) responsável da escola.

Após o aceite da escola, foi realizada uma reunião com os responsáveis para a explicação da pesquisa e recolha das assinaturas do Termo de Consentimento Livre e Esclarecido (TCLE) e solicitado o questionário sociodemográfico dos responsáveis que assentiram a participação das crianças na pesquisa. Posteriormente, houve uma apresentação da pesquisa às crianças, individualmente, e foi pedido a elas que assinassem o Termo de Assentimento Livre e Esclarecido para início da coleta. A coleta foi realizada de maneira individual, em sala de aula e/ou espaços reservados das escolas participantes.

Às crianças, então, foi realizada a seguinte pergunta: "O que é uma família para você?". Tais informações foram fornecidas verbalmente pelas crianças sem qualquer delimitação de tempo para as respostas. Todas as informações foram escritas e também gravadas em aparelho gravador para posterior análise. Após a coleta, todos os materiais foram recolhidos, mantidos em local seguro e sigiloso, de maneira que apenas a pesquisadora responsável e sua equipe tiveram acesso. Não foi utilizada nenhuma identificação pessoal para cada participante que coincidisse com os dados de realidade mantendo, assim, o anonimato dos participantes.

\section{Procedimentos de análise}

As respostas das crianças foram armazenadas em áudio e em formato de texto eletrônico. A análise dos dados contou com duas etapas. Em um primeiro momento, foi realizada uma análise quantitativa utilizando o programa $\mathrm{IRaMuTeQ}{ }^{\circledR}$ (Interface de R pour les Analyses Multidimensionnelles de Textes et de Questionnaires). O programa forneceu uma análise lexical de palavras presentes nas falas das crianças. Esse material foi armazenado em um corpus textual a ser interpretado pelo programa. Nuvem de palavras é uma das análises possibilitadas pelo uso do software. Trata-se de um recurso gráfico que agrupa termos frequentes mencionados pelos participantes, promovendo identificação de palavras-chaves. Foi possível realizar, ainda, uma análise de similitude, baseada na teoria dos grafos (teoria que demonstra ligações entre termos). Tal análise tem função de demonstrar graficamente a conexidade entre as palavras identificadas no corpus textual (Camargo \& Justo, 2013). Essa pode ser uma maneira de indicar, em uma subcultura tal qual a carioca estudada, com que outros estímulos a palavra "família" tem sido associada, e possivelmente indicar o tipo de relação estabelecida entre as palavras encontradas no discurso (coordenação, oposição e hierárquica).

Em um segundo momento, foi realizada uma análise qualitativa das respostas fornecidas pelas crianças, baseada na análise de conteúdo de Bardin (2011), incluindo: 1) pré-análise, 2) exploração do 
material e 3) tratamento dos resultados, inferência e resultados. Na primeira fase foi realizada uma leitura de conhecimento do texto (leitura flutuante), seguida por uma demarcação do conteúdo a ser recortado. Foram formulados objetivos, hipóteses teóricas e indicadores de pesquisa por meio de recortes do texto. Em seguida, na segunda etapa, o material foi explorado por meio da definição, codificação e classificação de categorias e, a partir disso, foi possível realizar uma análise descritiva. Por fim, na terceira fase, com intenção de fundamentar os resultados da pesquisa, foram realizadas análises inferenciais, reflexivas e críticas.

\section{Resultados e discussão}

\section{Análise lexical}

A análise lexical teve como objetivo apontar a frequência de palavras reportadas nas respostas das crianças à pergunta "O que é uma família para você?". Além disso, foram demonstradas as conexões entre as palavras pronunciadas. Em um primeiro momento, as respostas dos participantes ( $n=108)$ foram lidas com a pretensão de conhecimento do conteúdo dos relatos. Em seguida, essas respostas foram analisadas por meio do IRaMuTeQ (Camargo \& Justo, 2013).

A primeira etapa realizada foi unir todas as respostas ou textos e, assim, transformá-las em um corpus ou conjunto de textos. Nesse momento, cada resposta foi lida, atendendo às orientações do programa de excluir e substituir símbolos que podem impedir ou causar erros na análise realizada pela interface - e.g., hifens, aspas, travessões(Camargo \& Justo, 2013).

Após a confecção do corpus da pesquisa, foi realizada a análise de dados textuais: a lexicografia básica. Assim, serão apresentados aqui cálculos de frequências de palavras presentes em dois tipos de análises: 1) nuvem de palavras e 2) análise de similitude. A primeira análise é responsável por agrupar as palavras que mais se relacionam entre si, organizando-as por meio de um gráfico. Foram selecionadas como palavras de interesse (formas ativas) os adjetivos, substantivos, verbos, advérbios e formas não reconhecidas pelo dicionário do IRaMuTeQ. A segunda análise baseia-se na teoria dos grafos, a qual permite identificar a relação entre palavras, como tipo de conexão entre as palavras dos relatos (Camargo \& Justo, 2013).

\section{Nuvem de palavras}

A análise nuvem de palavras representa a frequência de palavras usadas nos relatos das crianças. Quando questionadas sobre o que é família, as crianças da amostra identificaram, principalmente, as seguintes palavras associadas ao construto: família $(n=96)$, não $(n=52)$, muito $(n=42)$, gente $(n=40)$, estar $(n=35)$, mãe $(n=33)$, ficar $(n=32)$, pai $(n=31)$, amor $(n=27)$, amar $(n=24)$, quando $(n=24)$, coisa $(n=23)$, junto $(n=23)$, feliz $(n=$ $22)$, sempre $(n=22)$, entre outras. Algumas palavras apareceram apenas uma única vez $(n=1)$, como emoção, esperança, funk, inimigo, cachorro, cobertor, companheirismo, conselho, coração, desobedecer, bondade, entre outras.

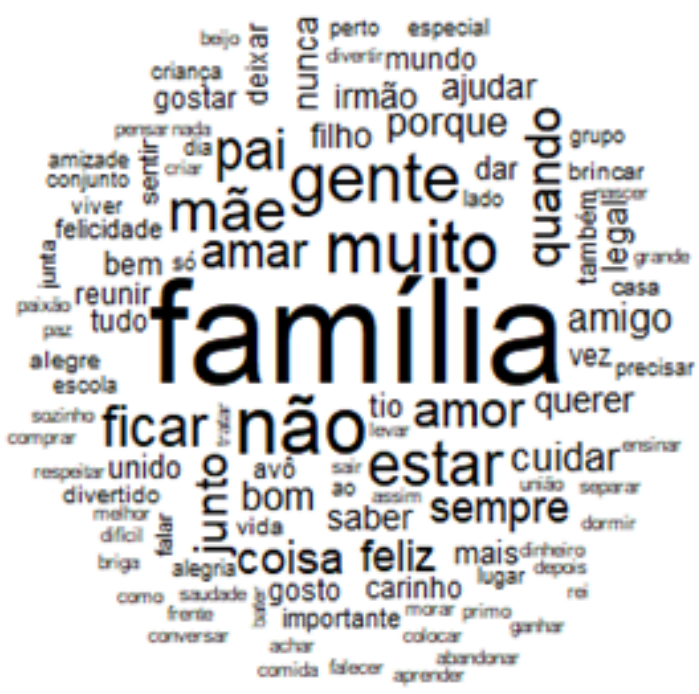

Figura 1. Nuvem de palavra 


\section{Análise de similitude}

Esta análise realizada pela interface IRaMuTeQ possibilita que sejam escolhidos parâmetros para a construção de uma árvore em que sejam visualizadas as coocorrências entre palavras. Foram mencionadas 377 palavras pelas crianças participantes. Essas palavras foram agrupadas pelo programa de acordo com a proximidade e distanciamentos das palavras citadas.

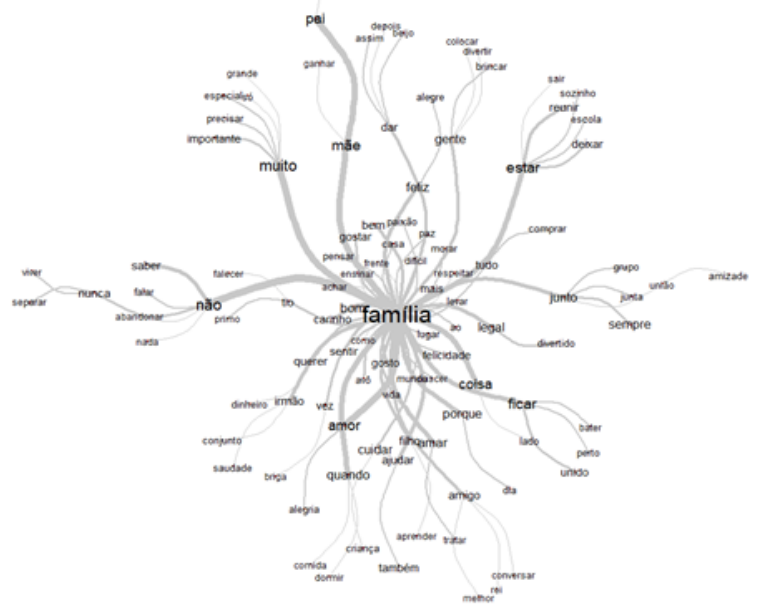

Figura 2. Análise de similitude

No centro do gráfico apareceu a palavra família $(n=96)$ associada às ramificações de palavras utilizadas com mais frequência: não $(n=52)$, muito $(n=42)$, estar $(n=35)$, mãe $(n=34)$, ficar $(n=32)$, amor $(n=27)$ e coisa $(n=23)$. A palavra mãe foi vista associada à palavra pai $(n=31)$, esta, por sua vez dita em menor frequência, e ambas associadas ao verbo criar ( $n=3$, e.g., "Um pai e uma mãe que te criaram"). Por outro lado, a palavra mãe esteve associada ao verbo ganhar $(n=3$, e.g., "Queria que minha mãe arranjasse um emprego, porque ela ganharia um emprego"). A justificativa pode ter relação com o fato de a mãe ainda assumir, culturalmente, os cuidados básicos dos filhos, como alimentar, cuidar e acompanhar em maior frequência quando comparado ao gênero masculino (Silva \& Laurenti, 2016; Vieira, Bossardi, Gomes, Bolze, Crepaldi \& Piccinini, 2014).

A palavra 'não', que indica relações de oposição, esteve associada às palavras saber $(n=15)$, nunca $(n=15)$, falar $(n=5)$, separar $(n=4) \mathrm{e}$ abandonar $(n=3)$, representando a concepção de separação e abandono (e.g., "São pessoas felizes, reunidas, uma ajudando a outra. Nunca se separam e vivem um pelo outro"). Essas palavras aparecem como estímulos distintos ao estímulo família por meio de uma relação de oposição (Hayes et al., 2001). Uma relação de oposição considera que as palavras mencionadas possam ser consideradas contrárias à família. Nesse sentido, a sensação de abandono e/ou separação aparece de um lado, enquanto a família permanece de outro, caracterizando 'família' como aquela que não abandona ou passa por separações.

Por outro lado, as crianças também consideraram determinadas palavras em relações de coordenação ou correspondência com a palavra família. $\mathrm{O}$ termo em questão (e.g., família) e outras palavras podem ser relacionados de maneiras similares e semelhantes (Hayes et al., 2001). Em uma lógica simbólica, as crianças mencionaram que determinados estímulos discutidos a seguir podem ser aproximados à família. Isso pode ser visto quando a palavra 'junto' (ligada à família) apareceu associada a dimensões de 'grupo', 'amizade', 'união'. Do mesmo modo, o verbo 'ficar' permaneceu associado às noções de proximidade quando associado às palavras unido $(n=12)$, perto $(n=6) \mathrm{e}$ lado $(n=5)$ (e.g., "Pessoas unidas que nunca vão se separar nem quando ficarem velhinhas. Essas pessoas sempre vão viver no meu coração"). Em consonância, a palavra junto também surgiu ao lado de palavras que indicam a mesma função de proximidade: grupo $(n=5)$, junta $(n=5)$, amizade $(n=5)$, união $(n=3)$ (e.g., "Grupo que não se separará e ficará para sempre junto. Uma pessoa companheira, seu melhor amigo, grupo companheiro que não vai deixar ninguém"). 
A palavra amor esteve associada a amar ( $n$ $=24)$, cuidar $(n=19)$, amigo $(n=18)$, querer $(n=$ $16)$, ajudar $(n=15)$, irmão $(n=15)$, filho $(n=14)$, gosto $(n=10)$, sentir $(n=9)$, alegria $(n=6)$, criança $(n=5)$, dinheiro $(n=4)$, saudade $(n=4)$, comida $(n=3)$. Nesse sentido, entende-se que a dimensão amor e/ou afeto foram associadas ao suprimento de cuidados básicos (e.g., comida, cuidar, ajudar, "Cuidam da gente quando estamos doentes"), provimentos materiais (e.g., dinheiro, "vai sempre gostar de você e vai comprar as coisas se tiver dinheiro") e relação de amizade (e.g., conversar, amigo, "É um lugar que todo mundo se ama [...]. São nossos primeiros amigos"). Verifica-se uma relação de equivalência de estímulos, mencionando que o estímulo 'família' pode significar o mesmo que o estímulo 'amor' e derivados (Hayes et al., 2001).

As palavras "pai" e "mãe" estiveram associadas entre si numa relação hierárquica com família, denotando que, na concepção das crianças entrevistadas, a família ainda pode ter enquanto exigência para se constituir como tal, a configuração tradicional. Tanto a análise lexical como a análise de conteúdo discutida a seguir apontaram para concepções que indicam famílias como espaços de afeto e de modelos tradicionais (mãe e pai), com outros membros ou não representados ao redor delas.

\section{Análise de conteúdo}

Os procedimentos adotados para a análise de conteúdo foram os seguintes: a) leitura das respostas das crianças para a pergunta "O que é uma família para você?”, b) identificação de respostas que se aproximavam em termos de conteúdo, dispondo-as em categorias, c) nomeação das categorias (núcleos temáticos) conforme conteúdo em comum, d) tratamento de resultados, inferência e interpretação de dados dispostos nos núcleos temáticos (Bardin, 2011). Considerando tais passos, foram apontados os seguintes núcleos temáticos discutidos a seguir: 1) família como espaço de afeto, 2) família como provedora, 3) família como conjunto de amigos, 4) famílias a partir de modelos específicos.

\section{Família como espaço de afeto}

Os discursos expressos nesta categoria estão relacionados à família associada às concepções de "amor", "carinho" e ao verbo "amar". Do ponto de vista analítico-comportamental, o indivíduo denomina o que sente de 'amor' por meio de uma perspectiva de fora para dentro, considerando, principalmente, o ponto de vista externo. Primeiramente, observa o que outro faz e o ama a partir das consequências recebidas pelos outros. Nesse sentido, o amor pode ser visto como um repertório de respostas afetivas a serem aprendidas observando os outros (Guilhardi, 2017; Skinner, 1991). As falas das crianças sugerem uma concepção de família associada à dimensão de amor quando aparece como fonte de reforçamento positivo de ajuda, proteção, acompanhamento, cuidados básicos, assistência física e material, entre outras: "É um amor, carinho. É ter alguém ao meu lado. É uma pessoa que fica ao teu lado e te acompanhando". (Lia, 7 anos), "Família para mim é tipo um conforto. Quando brigo com alguém sua família te ajuda a ficar melhor e fazer as pazes com eles" (Bernardo, 11 anos).

A análise do comportamento considera que os comportamentos são selecionados pelos níveis filogenético, ontogenético e cultural (Skinner, 2003). Não seria diferente com a dimensão amorosa e/ ou afetuosa. Filogeneticamente, a criança nasce com potencial genético para sugar o seio materno, emitir determinados sons, acolher afagos, imitar e desempenhar uma gama de respostas reflexas incondicionadas (inatas). Desde o nascimento, ela já apresenta maiores chances de responder ao calor ameno, toque físico suave e voz amena. Nessa perspectiva, a presença dos primeiros cuidadores pode ser vista como uma fonte de reforçamento para a criança, em virtude de, no mesmo momento em que eles promovem o toque do carinho e a interação 
de maneira docilizada (estímulos reforçadores), protegem do calor e/ou frio intenso, barulho, objetos perigosos (eventos desagradáveis) (Guilhardi, 2017). A vinheta abaixo relaciona família à função de auxiliar na sobrevivência de seus membros:

É legal pra mim. Sem minha família não sou nada. Se minha mãe não me colocasse no mundo, eu não tava aqui. Eu tenho amor e carinho por eles. Eu queria mais uma pessoa na minha família: um irmão. Família é tudo! Minha família tem amor, carinho e eles são alegres. Isso que é família. (Lina, 10 anos)

No trecho fica claro que, além de gerar uma criança, os pais e/ou cuidadores funcionam como os primeiros indivíduos a fornecerem os estímulos necessários para que a criança venha a se desenvolver integralmente (Tozze \& Bolsoni-Silva, 2018). De acordo com o nível ontogenético, comportamentos são selecionados no processo individual de desenvolvimento. São consideradas as experiências pessoais dos indivíduos, incluindo suas histórias individuais de reforçamento (Skinner, 1991; Skinner, 2003). Por isso, não basta "colocar no mundo", conforme a fala de Lina, mas fornecer ambiente para que a criança possa crescer com acesso a reforçadores positivos.

A cultura, terceiro nível de seleção dos comportamentos, aparece como responsável por selecionar os comportamentos necessários para que um grupo específico sobreviva (Skinner, 2003). Nesse sentido, o que é reforçador positivo para um membro do grupo tem chances de se tornar reforçador positivo para o outro, assim como o que é evento desagradável para um membro pode vir a se tornar um evento desagradável para o outro (Guilhardi, 2017).

João Marcos, 10 anos, relatou família como "Um conjunto de amor entre si. É um momento muito especial para um pai e mãe o de ter um filho e formar uma família". Amar a família pode representar uma classe de respostas a começar pelos pais (amar-se entre si) e se estender para toda a família (amar a todos os membros). Os pais fornecem os primeiros modelos de amor, importante para a sobrevivência da criança e, assim, o grupo também sobrevive. As crianças, ao começarem a imitar os adultos vão emitindo respostas de cuidado uns com os outros (Hirsh, Stockwell \& Walker, 2014), conforme relato de Míriam, 6 anos "Temos que amar a família para ficar juntos, ajudar o nosso pai a fazer vitamina, porque ele gosta”. Nesse sentido, os comportamentos de cuidados e/ou agrados uns em relação aos outros favorecem ao grupo (no caso, a família) permanecer coeso e com noções de bem-estar entre membros (Guilhardi, 2017).

A concepção afetuosa da família também esteve relacionada ora com a proximidade física ora com a distância (saudade). De um lado, a família apareceu como alguém que está sempre por perto, como aquela que "Nunca vai te deixar sozinho. Sempre vai ter alguém para dar a mão" (Andréa, 9 anos). Por outro lado, também foram consideradas pelas crianças famílias formadas por pessoas que não estão mais presentes, seja do ponto de vista de não morar junto, ausência momentânea ou de já ter falecido:

Tudo de bom. Felicidade estar perto deles. Não sair de perto deles. Saudades quando vão trabalhar, quando saem para o mercado e me deixam com a vizinha, quando minha irmã fica com amiga da minha mãe. Sinto saudade do meu irmão que mora em Minas, do meu irmão, que sou do $3^{\circ}$ e ele do $2^{\circ}$. Família é muita coisa de bom. (Ruan, 9 anos)

Em uma pesquisa realizada com 60 crianças mexicanas e 60 crianças francesas entre cinco e 13 anos de idade, sobre concepções acerca de famílias, $40 \%$ da amostra $(n=48)$ afirmaram que quando alguém se muda não pertence mais à família. Quanto mais novas as crianças, maiores os indícios de conceberem família pela proximidade espacial. Quanto mais velhas, maior a tendência a considerar que o tempo de coabitação era a justificativa para manter os laços familiares (Day \& Marie-José, 1999). Tais 
resultados, quase duas décadas depois, tendem a se afastar dos resultados expressos neste estudo. Isso pode ter relação com a maior expansão de modelos de famílias não tradicionais no Brasil (IBGE, 2014), de maneira que há um maior número de crianças convivendo com genitores e outros membros que não compartilham residência em outros espaços físicos. Os membros não residentes foram lembrados nas falas das crianças como constituintes da família, seja quando expressaram sentimentos de membros falecidos, seja quando residiam fora de casa ou em outro estado:

É agradável e muita saúde (família), porque come juntos alguns dias. Com muita paz, porque alguma parte da família não está com a gente em casa. Minha tia, meu tio e vô faleceram. Meu tio faleceu, porque tava na moto e um caminhão bateu de frente e eles faleceram. (Vitor, 8 anos)

Os resultados da presente pesquisa indicaram consonância com a literatura (e.g., Anyan \& Pryor, 2002; Rigg \& Pryor, 2007; Zabriskie \& McCormick, 2003), em que a maioria das concepções sobre famílias tem como resultado uma definição que engloba fatores afetivos (e.g., amor, cuidado e respeito), relações de sangue e residência com os pais. Os critérios mais importantes para definir família na amostra deste estudo foram as noções de afeto evidenciadas por uma convivência próxima ou queixas de quando a convivência não é tão frequente.

\section{Família como provedora}

A família como provedora é extraída dos relatos a partir de dois pontos de vistas: (1) cuidados básicos e/ou educacionais e (2) de materiais e/ou bens de consumo. Em um primeiro momento, as crianças da amostra atrelaram à concepção de família como a responsável por fornecer seus cuidados básicos e/ ou educacionais (tabela 1). A família aparece com a função primordial de oferecer cuidados básicos às crianças:

Rocha e Gurgel (2018) afirmam que pais e cuidadores desempenham a função de socialização das crianças na medida em que incentivam comportamentos relevantes para conviver em comunidade. Para tanto, eles organizam cuidados e acesso à educação com o intuito de favorecer interações das crianças entre pares, famílias e sociedades. O estudo de revisão sistemática de Vieira et al. (2014) mostrou que essas responsabilidades ainda são relacionadas principalmente às mães. No entanto, a literatura sugere um momento atual de transição entre o reconhecimento da importância da participação do pai no desenvolvimento da criança sem que ele apareça como ausente ou um mero "ajudante" da mãe (Silva \& Laurenti, 2016).

Tabela 1

Família como provedora de cuidados básicos

\begin{tabular}{lc}
\hline \multicolumn{1}{c}{ Vinhetas } & Tipo de cuidado básico \\
\hline "A família tem orgulho um do outro. Elas se ajudam. Fazem coisas juntos. Cuidam & \\
um do outro, ate dos filhos. Quando vai dormir, minha mãe faz Nescau pra mim. & Alimentação/colocar para dormir \\
Meu pai me dá um beijo.” (Felipe, 7 anos) & \\
“(...) pessoas que me fazem sempre felizes, são muito especiais para a minha vida. & \\
$\begin{array}{l}\text { Quero sempre perto de mim, tipo se eu tivesse doente, eles me dessem atenção. } \\
\text { (Bianca, 7 anos) }\end{array}$ & Cuidados na doença \\
"É aquela que dá carinho pra gente, que coloca o cobertor pra gente dormir, conversa & \\
$\begin{array}{l}\text { com a gente, brinca com a gente, se importa como a criança tá se alimentando e se } \\
\text { comportando na escola, se tá estudando. Uma família que faz a gente estudar e } \\
\text { depois que a gente cumpre, a gente pode ter nosso direito: brincar. (Jéssica, 8 anosono }\end{array}$ & \\
\hline
\end{tabular}


Acho que família é muito legal para quem precisa muito da família. Acho que minha amiga Raquel, porque o pai não gosta, não liga, não dá pensão. Diria que família é muito legal, porque pode conversar com ela, contar algo que aconteceu na escola. (Sara, 8 anos)

A paternidade foi revista desde o período em que a mulher conquistou espaços externos às paredes de casa em termos de deliberação de leis e a possibilidade de emitir um leque de comportamentos até então não autorizados, como o de trabalhar (Silva \& Laurenti, 2016). Assim, o pai teve que desenvolver repertórios de habilidades que atendessem às demandas realizadas pelas mães, como as que incluíam cuidados com os filhos e com a casa. Dessa maneira, foram revisados os padrões de comportamentos realizados entre genitores e filhos (parentalidade) e homens e mulheres (conjugalidade). Quando há um acordo entre os genitores, há espaço para maior envolvimento do pai na educação e responsabilidade dos filhos. Apesar desse acordo conjugal nem sempre ser possível, alguns estudos na área de família, como o de Mosmann, Costa, Silva e Luz (2018), garantem que há um crescimento no número de pais e homens que anseiam por maior envolvimento na criação de seus filhos.
Em outro momento, a família apareceu como a responsável por prover materiais e/ou bens de consumo. As crianças retrataram uma família cuja responsabilidade é fornecer bens de consumo (brinquedos, alimentos específicos) e de lazer (passeios e viagens). O materialismo é definido quando os bens e materiais sejam vias de acesso para a felicidade e desenvolvimento social do indivíduo (Grant, 2014). Um dos antecedentes e motivadores para o materialismo sugerido pela literatura há muitas décadas é a família (Rindfleisch \& Burroughs, 1997). Para os autores, bem como para a análise do comportamento, essa dimensão começa a ser aprendida com os pais (Bandura, Ross \& Ross, 1961; Hirsh et al., 2014) por observação vicária ou imitação. Os pais se relacionam com o consumo por meio do espaço em que vivem, despesas obtidas e pela interferência da aquisição de bens no orçamento familiar.

Além disso, admite-se que não há nenhum episódio na vida do indivíduo em que ele se encontre plenamente saciado dos reforçadores existentes, servindo de base para a explicação de que, independentemente da classe econômica, o comportamento de consumir está presente (Franceschini \& Hunziker, 2011; Grant, 2014). Isso pode explicar a presença do verbo "querer" nas falas das crianças.

Tabela 2

Família como provedora de materiais elou bens de consumo

Vinhetas

\footnotetext{
"Me dá tudo que eu quero" (Marcelo, 10 anos)

“Ai. Isso aí eu não sei. Ai. É difícil pensar. Uma família é tudo para mim. Ela me dá tudo que eu quero. Porque um dia queria uma boneca cara e minha mãe comprou pra mim. Queria que minha mãe arranjasse um emprego, porque ela ganharia mais dinheiro." (Fábia, 7 anos)

"Bom, porque eu não fico sozinho e ela também me dá leite. Eu pedi uma bola e minha mãe comprou. Tudo que eu falo ela diz que depois, porque tá tudo caro. Ela passeia no shopping comigo e minha irmã, me leva no trabalho dela e me dá lanche. Família é amor e ajudar ao próximo e quem não tem dinheiro.” (Gabriel, 7 anos)

"Uma família que cuida da gente pra a gente crescer. Eles ajudam a gente. Quando a gente quer uma coisa eles dão pra gente, tipo comida, passeios." (Carolina, 7 anos)

"Nunca pensei isso antes. A minha família é tipo a minha vida. Às vezes eles me dão coisas e eu gosto deles assim. Às vezes beijos. Não sei." (Larissa, 9 anos)
} 
No caso, brinquedos, alimentos e opções de lazer, objetos de consumo do mesmo, são vistos como estímulos reforçadores definidos por Skinner (2003).

\section{Família como conjunto de amigos}

A amizade em uma perspectiva analítico-comportamental pode ser explicada pelo nível ontogenético de seleção de comportamentos. Trata-se de vivências particulares de sensações de cooperação e proteção, que podem acontecer em determinados grupos familiares. Sentimentos de amizade podem representar um indivíduo ganhando algo que provenha do outro (Guilhardi, 2017). Isso pode ser visto na seguinte fala de Júlio, 10 anos, sobre família:

Hum! É... Hum...Não sei responder, mas vou responder mesmo assim. É um lugar que todo mundo se ama. Moram juntos. Sempre estão felizes para fazer qualquer coisa. São nossos primeiros amigos.

Nesse caso, pode não se tratar de uma proteção recíproca, noções de fraternidade e companheirismo, na medida em que é sugerida a existência de uma relação unilateral de ganho quando está em jogo o que eles (membros das famílias) podem oferecer para a criança. Essa, por sua vez, está aberta a receber cuidados exclusivos sem mencionar noções de mutualidade, como informar o que ela faz em relação aos pais e/ou cuidadores, irmãos e parentes (Guilhardi, 2017).

As sensações de bem querer e segurança manifestadas pelas crianças da amostra podem funcionar como estímulos reforçadores para a manutenção delas em grupos familiares durante a infância e prolongamento do seu desenvolvimento (Weber, 2017): "Legal. Tem gente. Pode conversar. Pode ter amigos. Pode brincar. Pode jogar bola" (Paulo, 9 anos). A concepção de proteção e segurança atrelada à família também aparece nos relatos das crianças:

Gosto muito das minhas famílias. Tipo amizade.

Sinto muita alegria em ter eles por perto. Sempre quando vou dormir, minha mãe segura a minha mão e fica comigo. (Janaína, 9 anos)

Em relação ao nível cultural, um valor evidenciado na cultura latina tem sido denominado como "familism" ou familismo (Hernández \& Bámaca-Colbert, 2016; ver também Wahler \& Cerezo, 2005, que relatam diferenças marcantes em criar filhos em cultura americana e espanhola). Refere-se à ligação do indivíduo com a família nuclear e estendida, determinando sentimentos intensos de lealdade, reciprocidade e solidariedade entre os seus membros (Stein, Gonzalez, Cupito, Kiang \& Supple, 2015). Pesquisas sugerem que isso contribui para melhorar o estado de saúde mental dos latinos em comparação a grupos minoritários na medida em que é fornecido um apoio natural em prol do crescimento de seus membros e proteção contra estressores (Hernández \& Bámaca-Colbert, 2016; Stein et al., 2015). No presente estudo, essa percepção da família como conjunto de membros amigos pode representar o apoio social da família. A conexão com as famílias pode funcionar, inclusive, para manter uma autoavaliação positiva e um senso de eficácia necessário para enfrentar barreiras presentes na vida das crianças e adolescentes (Stein et al., 2015).

Outra justificativa para a concepção de família estar associada a um conjunto de amigos pode ter relação com o fato de a amostra conter em sua maioria crianças menores de 12 anos. Isso porque, no decorrer do crescimento, o adolescente vai comumente se aproximando de grupos de pares e, consequentemente, afastando-se das famílias de origem e de adultos em geral (Furtado, Morais \& Canini, 2016).

\section{Famílias a partir de configurações específicas}

Família tradicional é entendida como uma organização familiar composta por pai, mãe e filhos, em que a mulher pode atuar como cuidadora dos 
filhos, do marido e do lar, enquanto o homem aparece como provedor do sustento econômico e financeiro (Del Priore, 2016). No entanto, apesar de as crianças representarem pai e mãe como os constituintes da família, não reportaram questões relacionadas às funções específicas de gênero, conforme proposto no modelo de família tradicional. Paula, 12 anos, informou que:

Uma família é tipo meu pai estar junto com minha mãe, e não com minha madrasta. Porque no dia dos pais eu vou estar junto com meu pai sem minha mãe e eu queria estar junto com eles e meus irmãos. No dia das mães a mesma coisa. No meu aniversário não posso ficar com os dois, porque minha mãe não pode ver meu pai, se não ela quer pegar ele, bater. Não sei a verdadeira história. Meu pai diz que minha mãe bebia, ela que era traição.

A pergunta "O que é uma família para você?" foi mobilizadora para que Paula contasse sobre litígios familiares envolvendo os genitores. Atualmente, a menina reside com a irmã, no entanto, não fez referência à irmã como família, e sim, retomou para o modelo tradicional desempenhado por casal e filho(s).

Apesar de serem evidentes as mudanças dos modelos familiares, não foi encontrada nenhuma referência capaz de evidenciar com clareza essas modificações. Quando não se tratava de uma família tradicional (pai, mãe e filhos), a referência das crianças era de uma família extensiva, que incluíam figuras como irmãos e avós.

Uma família para mim é tipo uma colônia, mas divertido. Tem uma colônia de filhos e os reis são pai e mãe. Uma família significa muito para mim, mais que uma família de amigos. Família são importantes porque um amigo pode ser amigo de um amigo que é de outra família. Uma família é como uma família de reis. Tios e tias são os cavaleiros e o vô e a vó são o rei e a rainha. A mãe e o pai são o príncipe e a princesa. Os filhos, eles vão para a escola para aprender a ser mosqueteiros, cavaleiros ou arqueiros. O vô e a vó estão no topo da família. Não. Eles estão nos primeiros lugares. O pai e a mãe não estão nos primeiros lugares. Em 1800, 1900, a família está unida. Hoje ainda está. Nunca vai deixar de ser. Os primeiros lugares são tatataratataravó e tataratataravô. Os filhos podem ser o que quiser, imaginar aonde vão, para no futuro ser o que quer. (Luiz, 9 anos)

Algumas crianças incluíram em seus desenhos de famílias membros externos. Dessa maneira, a concepção não era de uma família formada por laços consanguíneos, e sim, mais uma vez, a que evidenciava a dimensão afetiva, quando relacionada à amizade e sensação de proximidade (Ribeiro \& Cruz, 2013), como as seguintes concepções sobre famílias: "São várias pessoas. Se eu estou com um amigo, ele é uma família, pois é importante para mim" (Rodrigo, 10 anos).

É pessoas reunidas, alegres e felizes. Você (pesquisadora) é minha tia não porque é irmã da minha mãe, mas tem muita gente da rua que é mais minha tia que da minha própria família. Tem mais gente que tá presente na minha vida mais. (Juliana, 10 anos)

Essas falas enaltecem que a estrutura familiar não é o único fator que influencia a percepção de família, e sim permanecer juntos, disponibilizar atenção, companhia e/ou algum investimento afetivo aparecem como fonte de reforçamento social para as crianças (Tozze \& Bolsoni-Silva, 2018).

Ainda que algumas crianças tenham se manifestado em relação à família extensiva ou a que incluía membros externos, o discurso das crianças sempre retornava para mãe e pai como figuras centrais, enquanto as outras figuras permaneciam periféricas (Ribeiro \& Cruz, 2013). Em consonância, a pesquisa de Wedemeyer Bickhard e Cooper (1989) concluiu que quando crianças tiveram que escolher entre várias fotos representando agrupamentos 
familiares, todas selecionaram a imagem com pai, mãe e filho(a). No entanto, quase três décadas depois, a concepção de uma família tradicional pareceu ter se mantido neste estudo.

\section{Considerações finais}

O objetivo do presente estudo foi analisar as concepções de famílias presentes no relato de crianças. Os relatos indicaram que tais concepções estão associadas ao afeto, à providência de cuidados e/ou bens materiais, à amizade e às concepções familiares associadas a modelos específicos, principalmente o tradicional (casal com filhos). Indivíduos que cumprem tal função, ainda que não necessariamente residam com a criança, podem também ser vistos como famílias para elas.

Um dos avanços deste estudo compreende o fato de boa parte das crianças terem dissertado sobre funções de famílias, indo além de noções de composição e da estrutura familiar. Porém, percebe-se que os relatos ainda não representam uma compreensão clara, por parte das crianças, em relação às possibilidades de outros modelos familiares que não os tradicionais. Ao mesmo tempo, percebe-se que as crianças já concebem famílias como ambientes permeados pelo afeto. Verificou-se, também, que as crianças referem as figuras paternas e maternas com atribuições definidas por meio do gênero, além de considerar a presença de ambos (e não apenas de único genitor) como mantenedores da família como fonte de reforçamento positivo.

O presente estudo apresentou um delineamento misto, propondo análises quantitativas e qualitativas do conteúdo advindo dos relatos das crianças, o que representa um avanço para a literatura nacional sobre o tema. Os limites encontrados estiveram relacionados com a baixa diversificação da amostra e com a análise realizada baseada em uma única pergunta. São necessários, ainda, novos estudos capazes de contemplar uma amostra mais ampla, de diferentes contextos regionais e que considere outras características socioeconômicas, religiosas e arranjos familiares. Tais estudos permitirão a ampliar o conhecimento sobre o tema.

\section{Referências}

Anyan, S. E., \& Pryor, J. (2002). What is in a family? Adolescent perceptions. Children \& Society, 16, 306-317.

Bardin, L. (2011). Análise de conteúdo. São Paulo: Edições 70.

Bandura, A., Ross, D., \& Ross, S.A. (1961). Transmission of aggression through imitation of aggressive models. Journal of Abnormal and Social Psychology, 63, 575-582.

Baumrind, D. (1966). Effects of authoritative control on child behavior. Child Development, 37, 887-907.

Brasil. Constituição da República Federativa do Brasil. Diário Oficial da União, Brasília, data da publicação: 5 de outubro de 1988.

Camargo, B. V., \& Justo, A. M. (2013). IRaMuTeQ: um software gratuito para análise de dados textuais. Temas em Psicologia, 21(2), 513-518.

Catania, A. C. (2006a). Antecedents and consequents of words. The Analysis of Verbal Behavior, 22, $89-100$

Catania, A. C. (2006b). Words as behavior. The Analysis of Verbal Behavior, 22, 87-88.

Day, E. D., \& Marie-Jose, R. (1995). Mexican and French children's conceptions about family: A developmental approach. Journal of Comparative Family Studies, 30(95).

Del Priore, M. (2016). Histórias da gente brasileira. São Paulo: Leya.

Dias, M. B. (2017). Manual de direito das famílias. São Paulo: Revista dos Tribunais.

Franceschini, A. C. T., \& Hunziker, M. H. L. (2011). Conciliando a economia e a análise do comportamento no estudo da relação entre renda e comportamento de consumir. Revista Brasileira de Análise do Comportamento, 7, 29-44. 
Furtado, A.G., Morais, K. S., \& Canini, R. (2016). O direito à convivência familiar e comunitária de crianças e adolescentes: construção histórica no Brasil. Serviço Social Revista, 19(1), 131-154.

Grant, L. K. (2014). Insatiability: part of the problem or part of the solution? Behavior and Social Issues, 23, 52-67.

Guilhardi, H. J. (2017). Interações amorosas sob uma perspectiva comportamental. Campinas: ITCR.

Hayes, S. C., Fox, E., Gifford, E. V., Wilson, K. G., Barnes-Holmes, D., Healy, O. (2001). Derived Relational Responding as Learned Behavior. Em S. C. Hayes, D. Barnes-Holmes, \& B. Roche (Orgs.), Relational frame theory; a post-skinnerian account of human language and cognition. New York: Plenum Press.

Hirsh, J. L., Stockwell, F., \& Walker, D. (2014). The effects of contingent caregiver imitation of infant vocalizations: A comparison of multiple caregivers. Analysis Verbal Behavior, 30, 20-28.

Instituto Brasileiro de Geografia e Estatística - IBGE. Estatísticas do Registro Civil: 2014. Rio de Janeiro: Ministério do Planejamento, Orçamento e Gestão. Disponível em http://biblioteca.ibge.gov.br/visualizacao/periodicos/135/ rc_2014_v41.pdf

Latham, G. I. (2012). The power of positive parenting: $A$ wonderful way to raise the children. North Logan: P \& T ink.

Maccoby, E., \& Martin, J. (1983). Socialization in the context of the family: Parent child interaction. Em E. M. Hetherington (Org.), Handbook of child psychology (V. 4, pp. 1-101). New York: Wiley.

Mosmann, C., Costa, C.B., Silva, M A. G. M., \& Luz, S. K. (2018). Filhos com sintomas psicológicos clínicos: papel discriminante da conjugalidade, coparentalidade e parentalidade. Temas em Psicologia, 26(1), 429-442.

Ribeiro, F. S., \& Cruz, F. M. L. (2013). Representações sociais de família por crianças na cidade de Recife. Psicologia \& Sociedade, 25(3), 612-622.
Rigg, A., \& Pryor, J. (2007). Children's perceptions of family: What do they really think? Children \& Society, 21, 17-30.

Rindfleisch, A., \& Burroughs, J. (1997). Family structure, materialism, and compulsive consumption. Journal of Consumer Research, 23, 312-326.

Rocha, T. M., \& Gurgel, P. R. H. (2018). Práticas parentais e análise do comportamento: o estado do conhecimento de teses e dissertações de 2010 a 2015. Série-Estudos, 23(47), 241-262.

Rosa, C. P. (2013). IFamily: Um novo conceito de família? São Paulo: Saraiva.

Silva, E. C., \& Laurenti, C. B. F. (2016). Skinner e Simone de Beauvoir: "a mulher" à luz do modelo de seleção pelas consequências. Perspectivas em Análise do Comportamento, 7(2), 197-2011.

Skinner, B. F. (2003). Ciência e comportamento humano. São Paulo: Martins Fontes.

Skinner, B. F. (1991). Questões recentes na análise comportamental. Trad. Anita L. Neri. Campinas, Papirus.

Stein, G. L., Gonzalez, L. M., Cupito, A. M., Kiang, L., \& Supple, A. J. (2015). The protective role of familism in the lives of Latino adolescents. Journal of Family Issues, 36, 1255-1273.

Tozze, K., \& Bolsoni-Silva, A. (2018). Intervenção em grupo com pais de adolescentes com problemas de comportamento internalizantes. Revista Brasileira de Terapia Comportamental e Cognitiva, 19(4), 6-24.

Vieira, M. L., Bossardi, C. N., Gomes, L. B., Bolze, S. D. A., Crepaldi, M. A., \& Piccinini, C. A. (2014). Paternidade no Brasil: revisão sistemática de artigos empíricos. Arquivos Brasileiros de Psicologia, 66(2), 36-52.

Wahler, R. G., \& Cerezo, M. A. (2005). The mothering of conduct problem and normal children in Spain and the USA: Authoritarian and permissive asynchrony. Spanish Journal of Psychology, 8(2), 205-214.

Weber, L. (2017). Eduque com carinho para pais e filhos. (6a ed.) Paraná: Juruá. 
Wedemeyer, N. V., Bickhard, M.H., \& Cooper, R. G. (1989). The development of structural complexity in the child's concept of family: The effect of cognitive stage, sex, and intactness of family. Journal of Genetic Psychology, 150, 342-357.

Wilson, K. G., \& Luciano, M. C. (2002). Terapia de Aceptación y Compromiso (ACT). Un tra- tamiento conductual orientado a los valores. Madrid: Pirámide.

Zabriskie, R. B., \& McCormick, B. P. (2003). Parent and child perspectives family leisure involvement and satisfaction with family life. Journal of Leisure Research, 35, 163-189. 